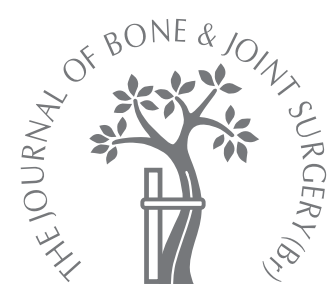

B. J. L. Kendrick,

D. Longino,

H. Pandit,

U. Svard,

H. S. Gill,

C. A. F. Dodd,

D. W. Murray,

A. J. Price

From Biomedical

Research Unit,

Nuffield Orthopaedic

Centre, Oxford, England Research Fellow

H. Pandit, DPhil, FRCS(Orth),

Senior Clinical and Research

Fellow

H. S. Gill, DPhil, University

Lecturer in Orthopaedic

Engineering

C. A. F. Dodd, FRCS, Consultant

Orthopaedic Surgeon

D. W. Murray, MD, FRCS(Orth)

Professor and Consultant

Orthopaedic Surgeon

A. J. Price, DPhil, FRCS(Orth),

Consultant Orthopaedic Surgeon

and Reader in Musculoskeletal

Science

Biomedical Research Unit,

Nuffield Department of

Orthopaedics, Rheumatology and

Musculoskeletal Sciences

Nuffield Orthopaedic Centre,

Windmill Road, Oxford OX3 7LD,

UK.

D. Longino, MD, FRCS(C),

Clinical Assistant Professor

Sports Medicine Centre

2500 University Drive $\mathrm{N}$

University of Calgary, Calgary,

Alberta, Canada T2N 1N4.

U. Svard, MD, PhD, Consultan Orthopaedic Surgeon

Department of Orthopaedics

Skaraborgs Sjukhus,

Kärnsjukhuset, SE-54185, Skövde,

Sweden.

Correspondence should be sent to Mr A. J. Price; e-mail:

andrew.price@ndorms.ox.ac.uk

(C2010 British Editorial Society of Bone and Joint Surgery doi:10.1302/0301-620X.92B3. $22491 \$ 2.00$

$J$ Bone Joint Surg $[\mathrm{Br}]$ 2010;92-B:367-73.

Received 23 February 2009;

Accepted after revision 2

November 2009

\title{
Polyethylene wear in Oxford unicompartmental knee replacement
}

\author{
A RETRIEVAL STUDY OF 47 BEARINGS
}

The Oxford Unicompartmental Knee replacement (UKR) was introduced as a design to reduce polyethylene wear. There has been one previous retrieval study involving this implant, which reported very low rates of wear in some specimens but abnormal patterns of wear in others. There has been no further investigation of these abnormal patterns. The bearings were retrieved from 47 patients who had received a medial Oxford UKR for anteromedial osteoarthritis of the knee. None had been studied previously. The mean time to revision was 8.4 years (SD 4.1), with 20 having been implanted for over ten years. The macroscopic pattern of polyethylene wear and the linear penetration were recorded for each bearing. The mean rate of linear penetration was $0.07 \mathrm{~mm} / \mathrm{year}$. The patterns of wear fell into three categories, each with a different rate of linear penetration; 1) no abnormal macroscopic wear and a normal articular surface, $n=16$ (linear penetration rate $=0.01 \mathrm{~mm} /$ year); 2) abnormal macroscopic wear and normal articular surfaces with extra-articular impingement, $\mathbf{n}=16$ (linear penetration rate $=0.05 \mathrm{~mm} /$ year); 3 ) abnormal macroscopic wear and abnormal articular surfaces with intra-articular impingement $+/$ - signs of noncongruous articulation, $n=15$ (linear penetration rate $=0.12 \mathrm{~mm} /$ year). The differences in linear penetration rate were statistically significant $(p<0.001)$.

These results show that very low rates of polyethylene wear are possible if the device functions normally. However, if the bearing displays suboptimal function (extra-articular, intraarticular impingement or incongruous articulation) the rates of wear increase significantly.

Polyethylene particulate wear debris continues to be implicated in the aetiology of aseptic loosening following knee replacement. ${ }^{1,2}$ The Oxford Unicompartmental Knee replacement (UKR) (Biomet, Swindon, United Kingdom) was introduced as a design to reduce polyethylene wear. ${ }^{3}$ The use of a spherical femoral component and a fully congruous meniscal bearing to increase the contact area theoretically reduces the potential for polyethylene wear. ${ }^{4}$ If a medial Oxford UKR is functioning normally, some abrasive and adhesive wear will occur at the articulations, but there should be minimal macroscopic wear and a low rate of wear overall. Any observed wear should be uniform. There has been one previous retrieval study of the medial Oxford UKR, which reviewed 16 bearings. ${ }^{5}$ Very low rates of wear were seen in some specimens, but in others abnormal patterns occurred. Impingement lesions were seen on the extra-articular aspects of the bearings, particularly anteriorly, and these were associated with higher rates of wear. There has been no further investigation of these abnormal wear patterns.
The primary aim of this study was to measure the rate of polyethylene wear for the medial Oxford UKR as a quantitative assessment. The secondary aim was to characterise the patterns of macroscopic wear, identifying normal or abnormal patterns as a qualitative assessment.

\section{Patients and Methods}

Between 1998 and 2003, 47 polyethylene bearings were retrieved at revision surgery from 47 patients previously treated with a medial Oxford UKR. The majority (32) were at the Nuffield Orthopaedic Centre, Oxford, and 15 were revised in Skövde, Sweden. For inclusion in the study each bearing must have been part of a phase 1 or 2 medial Oxford UKR used to treat patients with osteoarthritis. Phase 3 implants, introduced in 1998, were excluded to ensure that the study focused on long-term wear.

The patient demographics and details of the bearing and revision were obtained from the hospital records (Table I). A total of 11 retrievals were from phase 1 and 36 from phase 2 . 
The mean time to revision was 8.4 years (SD, 4.1). The most common causes for revision were the development of lateral compartment osteoarthritis, or aseptic loosening of components, found in 24 and 13 patients, respectively.

Qualitative assessment of polyethylene wear. All bearings were examined by two independent investigators (DJB, AJP) for the presence of abnormal wear patterns. Each was checked for impingement lesions, where polyethylene damage was found at the margins of the bearing, as described by Psychoyios et al. ${ }^{5}$ In addition any evidence of wear that encroached upon the superior or inferior articular surfaces of the bearing was noted. The presence of delamination, defined as loss of sheets of polyethylene from the articular surface of the bearing, and pitting, comprising small craters $<1 \mathrm{~mm}$ in diameter, ${ }^{5,6}$ was also noted. Pitting was divided into two subgroups in the manner described by Psychoyios et $\mathrm{al},{ }^{5}$ with minor pitting being defined as small occasional pits and severe pitting as multiple pits.

In order to document the reproducibility of these categorical measurements, the $\kappa$ statistic was used. ${ }^{7,8}$ The intra- and inter-observer $\kappa$ statistic for defining normal or abnormal wear patterns was 1 , showing perfect agreement; that for evaluating different patterns of abnormal wear (three groups) was 0.8 , representing good agreement, as defined by Fleiss, Levin and Paik. ${ }^{9}$

Quantitative assessment of polyethylene wear. Linear penetration of polyethylene bearings occurs from a combination of wear and creep. ${ }^{10} \mathrm{~A}$ number of studies have suggested that creep occurs mainly in the first three months after implantation of a polyethylene bearing. ${ }^{11,12}$ The proportion of true wear to creep will increase with time, reducing its significance in estimating the rate of wear. Retrieval studies do not allow the quantification of the degree of creep. With the mean time to revision in this study being over eight years, we believe that creep would have a relatively small effect on the calculated rate of wear for the majority of the bearings. Because of creep the measurement of penetration over-estimates wear. Therefore, for the purpose of this study, it was assumed that no creep had occurred and that all measured linear penetration was a direct representation of linear wear. If creep did contribute substantially to the measurement, it would be manifest as rapid early penetration.

In order to establish the linear penetration, the minimum thickness of each retrieved bearing was subtracted from the thickness of the bearing at insertion. The thickness was measured using a Mercer dial gauge (Tesa Technology UK Ltd, Telford, United Kingdom) with measuring arm and attached foot piece. The foot piece contacting the bearing surface had the same radius of curvature as the femoral component of the phase 1 and phase 2 implants $(23.8 \mathrm{~mm})$. The dial gauge was calibrated before commencing measurements using a M 2146 measuring machine (SIP, Geneva, Switzerland) and found to have a mean error of $0.0005 \mathrm{~mm}$ (SD 0.0013). Each bearing was measured three times and the mean of these values was taken as the minimum thick- ness of the bearing surface. The foot piece was placed in the lowest part of the articular surface to mimic the position of the femoral component. Although it had the same radius of curvature as a femoral component, it was considerably smaller and thus able to measure non-congruent regions of the articular surface. Although some bearings had large intra-articular defects, none a defect at the point of measurement. This method ensured a repeatable measurement that accurately assessed linear penetration and enabled reliable comparison between groups. Reproducibility of the quantitative assessment of retrieved bearings was tested using 25 bearings measured in the manner described above by two different investigators (DJB, AJP), as described by Bland and Altman. ${ }^{7,13}$ The inter- and intra-observer mean errors were $0.001 \mathrm{~mm}$ (SD 0.011) and $0.001 \mathrm{~mm}$ (SD $0.013)$, respectively.

A total of 20 of the 47 bearings had been autoclaved after retrieval and represented a potential source of measurement error. Psychoyios et $\mathrm{al}^{5}$ have shown that autoclaving increases bearing thickness secondary to heat distortion, independent of the nominal thickness. In order to examine the external validity of our system, 20 unused bearings were measured before and after autoclaving using a standard Motoclave Type SDA-PPK autoclave (British Sterilizer Ltd, Ilford, United Kingdom) for $3 \mathrm{~min} 20 \mathrm{~s}$ at $134^{\circ} \mathrm{C}$ to $137^{\circ} \mathrm{C}$. The mean increase in thickness was +0.33 $\mathrm{mm}$ (SD 0.06), a similar finding to those of Psychoyios et al. ${ }^{5}$ Furthermore, 20 of the retrieved bearings which had not originally been autoclaved were identified. Measurements of thickness were taken before and after sterilisation, revealing a mean increase in thickness of $0.41 \mathrm{~mm}$ (SD 0.05). Therefore, when calculating the thickness of the 20 autoclaved bearings from the retrieval study, a correction factor of $+0.41 \mathrm{~mm}$ was applied to the nominal thickness. The other 27 bearings had been washed in glutaraldehyde and then water prior to analysis, thereby avoiding this potential source of error.

There was no statistically significant difference in the calculated linear penetration rate for bearings that had been autoclaved $(0.06 \mathrm{~mm} / \mathrm{year}$ (95\% confidence interval (CI) 0.04 to 0.06$)$ or not autoclaved $(0.06 \mathrm{~mm} /$ year, $95 \% \mathrm{CI}$ 0.04 to 0.08 ) after retrieval.

The nominal thickness of each bearing at insertion is item specific and stamped on to the non-articulating surface of the polyethylene. Bearing thicknesses for phase 1 and phase 2 implants increased in $1 \mathrm{~mm}$ increments from size 0 $(3.5 \mathrm{~mm})$ to size $8(11.5 \mathrm{~mm})$. In order to investigate the manufacturers' tolerance, the thickness of 20 unused bearings (phase 2) were measured in an identical fashion to that described for retrieved bearings and compared with their nominal value. True bearing thickness was a mean of +0.05 $\mathrm{mm}$ thicker than the nominal thickness (SD $0.06 \mathrm{~mm}$ ). Therefore, for the purpose of this study, the bearing thickness at insertion was taken to be the stated nominal thickness plus $0.05 \mathrm{~mm}$. The final formula for calculating linear penetration including correction factors was: 
Table I. Summary of retrieved bearings with demographic details. A total of 20 of the bearings had been implanted for over ten years. The indication for revision of the prostheses is also shown

\begin{tabular}{|c|c|c|c|c|c|}
\hline Case & Phase & Gender & $\begin{array}{l}\text { Age at operation } \\
\text { (yrs) }\end{array}$ & $\begin{array}{l}\text { Time to revision } \\
\text { (yrs) }\end{array}$ & Reason for revision \\
\hline 1 & 1 & $\mathrm{~F}$ & 63.5 & 13.9 & Lateral compartment arthritis \\
\hline 2 & 1 & $\mathrm{M}$ & 58.1 & 8.5 & Lateral compartment arthritis \\
\hline 3 & 2 & $\mathrm{M}$ & 58.6 & 10.2 & Lateral compartment arthritis \\
\hline 4 & 2 & $\mathrm{M}$ & 56.3 & 7.5 & Lateral compartment arthritis \\
\hline 5 & 2 & $\mathrm{~F}$ & 51.6 & 7.8 & Lateral compartment arthritis \\
\hline 6 & 2 & $\mathrm{M}$ & 64.4 & 5.6 & Lateral compartment arthritis \\
\hline 7 & 2 & $\mathrm{M}$ & 88.0 & 12.0 & Lateral compartment arthritis \\
\hline 8 & 1 & $\mathrm{~F}$ & 52.5 & 15.4 & Lateral compartment arthritis \\
\hline 9 & 2 & $\mathrm{M}$ & 61.2 & 12.5 & Lateral compartment arthritis \\
\hline 10 & 2 & $\mathrm{M}$ & 61.9 & 5.7 & Lateral compartment arthritis \\
\hline 11 & 2 & $\mathrm{~F}$ & 67.5 & 4.0 & Lateral compartment arthritis \\
\hline 12 & 2 & $\mathrm{M}$ & 47.0 & 13.3 & Lateral compartment arthritis \\
\hline 13 & 2 & $\mathrm{~F}$ & 64.5 & 1.1 & Lateral compartment arthritis \\
\hline 14 & 2 & $\mathrm{~F}$ & 74.7 & 7.6 & Lateral compartment arthritis \\
\hline 15 & 2 & $\mathrm{M}$ & 68.0 & 10.5 & Lateral compartment arthritis \\
\hline 16 & 2 & $\mathrm{M}$ & 71.0 & 5.7 & Lateral compartment arthritis \\
\hline 17 & 2 & $\mathrm{~F}$ & 79.1 & 5.8 & Lateral compartment arthritis \\
\hline 18 & 2 & $\mathrm{~F}$ & 74.6 & 4.5 & Lateral compartment arthritis \\
\hline 19 & 2 & $\mathrm{~F}$ & 69.6 & 8.4 & Lateral compartment arthritis \\
\hline 20 & 2 & $\mathrm{~F}$ & 60.6 & 4.6 & Lateral compartment arthritis \\
\hline 21 & 2 & $\mathrm{~F}$ & 58.3 & 10.2 & Lateral compartment arthritis \\
\hline 22 & 2 & $\mathrm{M}$ & 52.6 & 5.8 & Lateral compartment arthritis \\
\hline 23 & 2 & $\mathrm{~F}$ & 65.5 & 9.0 & Lateral compartment arthritis \\
\hline 24 & 2 & $\mathrm{M}$ & 66.4 & 9.0 & Lateral compartment arthritis \\
\hline 25 & 1 & $\mathrm{~F}$ & 74.6 & 7.0 & Loose femoral component \\
\hline 26 & 1 & $\mathrm{~F}$ & 66.0 & 11.0 & Loose femoral component \\
\hline 27 & 1 & $\mathrm{~F}$ & 60.9 & 13.6 & Loose femoral component \\
\hline 28 & 2 & $\mathrm{~F}$ & 67.4 & 11.2 & Loose femoral component \\
\hline 29 & 2 & $\mathrm{M}$ & 54.5 & 6.8 & Loose femoral component \\
\hline 30 & 2 & $\mathrm{~F}$ & 85.3 & 6.4 & Loose femoral component \\
\hline 31 & 2 & M & 57.4 & 4.1 & Loose femoral component \\
\hline 32 & 1 & $\mathrm{M}$ & 68.6 & 5.7 & Loose tibial and femoral components \\
\hline 33 & 1 & $\mathrm{~F}$ & 73.6 & 11.3 & Loose tibial and femoral components \\
\hline 34 & 2 & $\mathrm{M}$ & 67.5 & 2.4 & Loose tibial and femoral components \\
\hline 35 & 2 & M & 60.9 & 11.4 & Loose tibial and femoral components \\
\hline 36 & 2 & M & 67.1 & 11.5 & Loose femoral components and dislocation \\
\hline 37 & 2 & $\mathrm{~F}$ & 72.4 & 5.9 & Loose femoral components and dislocation \\
\hline 38 & 1 & $\mathrm{~F}$ & 62.5 & 16.7 & Loose femoral components and dislocation \\
\hline 39 & 2 & M & 61.5 & 1.0 & Dislocated bearing \\
\hline 40 & 2 & $\mathrm{~F}$ & 68.1 & 12.8 & Dislocated bearing \\
\hline 41 & 2 & $\mathrm{M}$ & 67.7 & 12.0 & Dislocated bearing \\
\hline 42 & 2 & M & 48.1 & 0.7 & Dislocated bearing \\
\hline 43 & 2 & $\mathrm{M}$ & 61.3 & 12.2 & Fracture of meniscus \\
\hline 44 & 2 & M & 56.0 & 5.4 & Fracture of meniscus \\
\hline 45 & 2 & $\mathrm{~F}$ & 67.4 & 1.2 & Deep infection \\
\hline 46 & 1 & $\mathrm{~F}$ & 84.1 & 12.2 & Unexplained pain \\
\hline \multirow[t]{2}{*}{47} & 1 & $\mathrm{M}$ & 62.5 & 15.0 & Unexplained pain \\
\hline & & Mean (SD) & $64.8(9.0)$ & $8.4(4.1)$ & \\
\hline
\end{tabular}

$$
\left(\mathrm{T}_{\mathrm{N}}+\left(\mathrm{T}_{\mathrm{C}} \text { or } \mathrm{T}_{\mathrm{A}}\right)-\mathrm{T}_{\mathrm{R}}\right)=\text { Linear penetration }(\mathrm{mm})
$$

$\mathrm{T}_{\mathrm{N}}=$ Nominal thickness $=$ Bearing size $+3.5 \mathrm{~mm}$

$\mathrm{T}_{\mathrm{C}}=$ Tolerance correction thickness $=0.05 \mathrm{~mm}$ (applied if bearing not autoclaved)

$\mathrm{T}_{\mathrm{A}}=$ Autoclave correction thickness $=0.41 \mathrm{~mm}($ applied if bearing autoclaved)

$\mathrm{T}_{\mathrm{R}}=$ Thickness at retrieval $=$ Measured thickness $(\mathrm{mm})$ Estimation of linear penetration rate. The rate of linear penetration for each bearing was calculated by dividing the mea- sured penetration by the time to revision, with the average of these values representing the mean rate for the entire group. The error introduced by manufacturing tolerance of bearing thickness will have a proportionally greater impact on the estimated rate of penetration in implants that have been revised at an early stage, thereby reducing the accuracy of estimating the mean rate of wear in this manner. In this study, the linear regression method was employed. The calculated linear penetration for each bearing was plotted against time to revision. A regression line was applied to the data points 


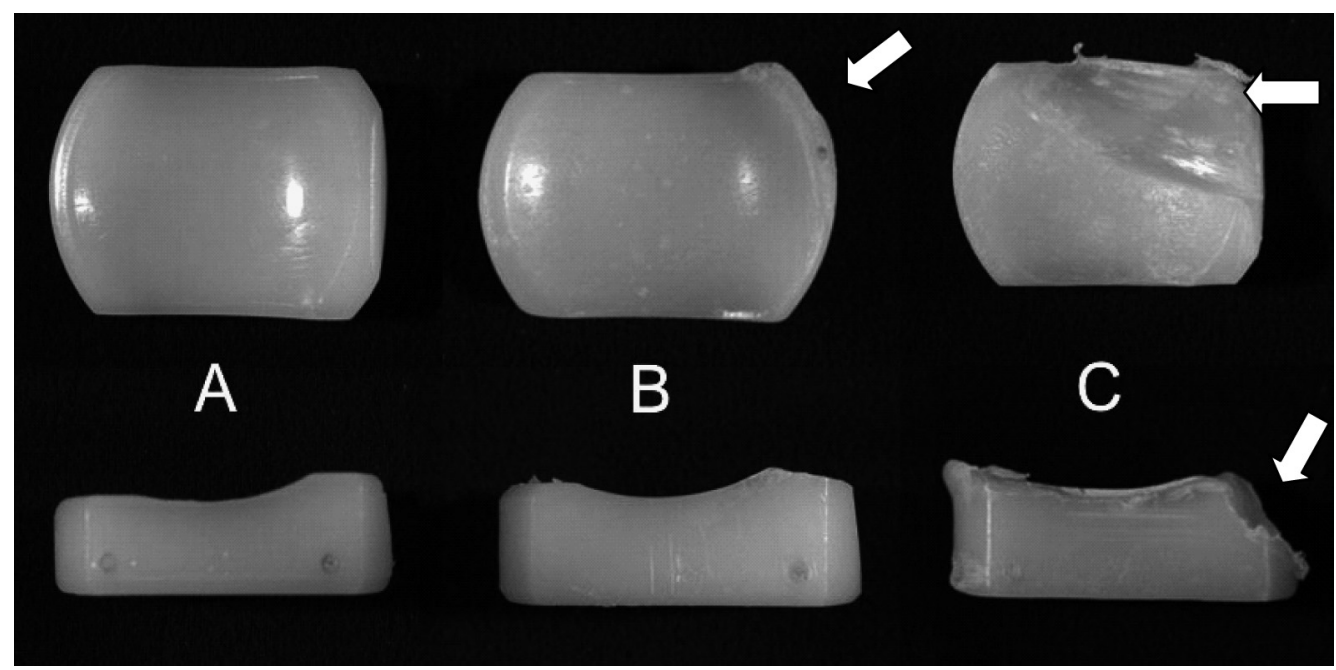

Fig. 1

Surface and lateral views of each pattern of macroscopic wear. (A) No abnormal wear. (B) Abnormal wear with extraarticular impingement (arrow to mark simple impingement lesion). (C) Abnormal wear with intra-articular impingement (arrow to mark where impingement has produced a large defect within the articular surface).

and constrained to pass through zero, as it was assumed that no wear had occurred at time zero after implantation. The gradient of the line represents an estimate of the rate of penetration for the entire group, and confidence intervals were calculated.

Pairwise comparison of the rate of penetration between subgroups is made by applying a $t$-test to the gradients. A sample size calculation determined that a group of 30 bearings $(15$ in each group) would give $90 \%$ power of detecting a $0.05 \mathrm{~mm} /$ year difference in rates of wear between two subgroups (SD $0.04 \mathrm{~mm} /$ year and $\alpha=0.05) .^{6}$ The SD for this calculation was taken from the historical data provided by Psychoyios et al. ${ }^{5}$

The incidence of impingement between the phase 1 and phase 2 components was compared with a chi-squared test, and of mean penetration according to bearing thickness with analysis of variance (ANOVA). For all statistical tests a p-value of $<0.05$ was considered significant.

\section{Results}

Macroscopic wear patterns. In all, 16 of 47 bearings showed no signs of impingement or abnormal wear. Although no surface delamination was noted, all except one of the bearings showed minor pitting. The remaining 31 showed abnormal wear patterns, with each bearing displaying evidence of impingement. A loss of polyethylene was found in 16 bearings at the anterosuperior aspect, confined to the extraarticular surface of the bearing (extra-articular impingement). In four cases there was concurrent posterior extraarticular impingement. All of these bearings had pitting, with the changes being severe in three cases. Of the remaining 15 bearings, six had an impingement lesion that encroached upon the articular surface (intra-articular impingement), with marked loss of polyethylene. One bearing had extension of the lesions beyond the midpoint in the anteroposterior plane. The surface damage to these bearings was more extensive, with areas of delamination in all cases, severe pitting in four, and minor pitting in two. The remaining nine bearings showed other abnormal wear patterns in addition to impingement lesions, suggesting that an incongruous articulation had occurred. Of these, five had longitudinal steps in the normally smooth articular surface of the bearing, and five bearings had uneven loss of polyethylene from the inferior surface of the component, signifying 'bottom-side wear'. All these bearings showed evidence of pitting and delamination. Two bearings with evidence of impingement and incongruous wear were found to have fractured.

In summary, three different groups of macroscopic patterns of wear were identified (Fig. 1):

Group A: no abnormal wear and a normal articular surface.

Group B: abnormal wear and normal articular surfaces with extra-articular impingement.

Group C: abnormal wear and abnormal articular surfaces with intra-articular impingement +/- signs of noncongruous articulation.

Measured linear penetration. A total of 43 of the 47 bearings had linear penetration into the polyethylene. One bearing remained the same thickness as its estimated thickness at insertion. The remaining three had minimal increases in size from the nominal thickness, with penetrations of $-0.01 \mathrm{~mm},-0.01 \mathrm{~mm}$ and $-0.03 \mathrm{~mm}$, probably reflecting error in estimating the nominal thickness at the time of insertion. The results for linear penetration against time to revision for all bearings are plotted in Figure 2. Using regression analysis, the estimated mean rate of linear penetration for the whole group of 47 bearings was $0.07 \mathrm{~mm} /$ year (95\% CI 0.06 to $0.09 \mathrm{~mm} /$ year). 


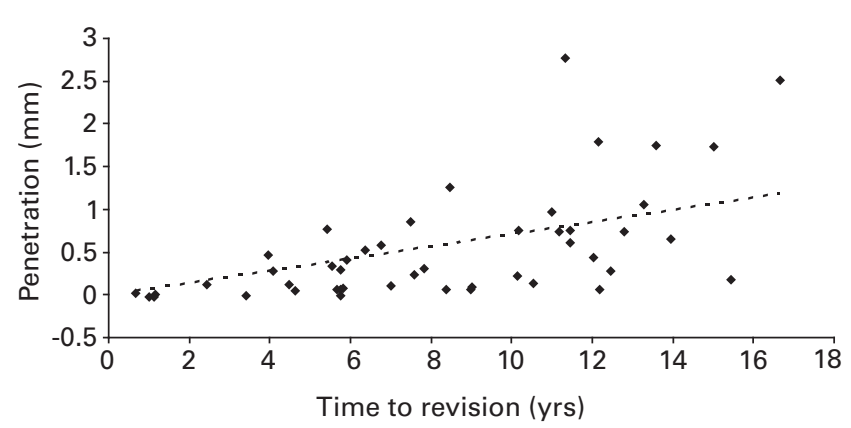

Fig. 2

Penetration plotted against time to revision (47 specimens), with regression line constrained to pass through zero. The mean rate of penetration is represented by the gradient of the line $(0.07 \mathrm{~mm} /$ year $)$.

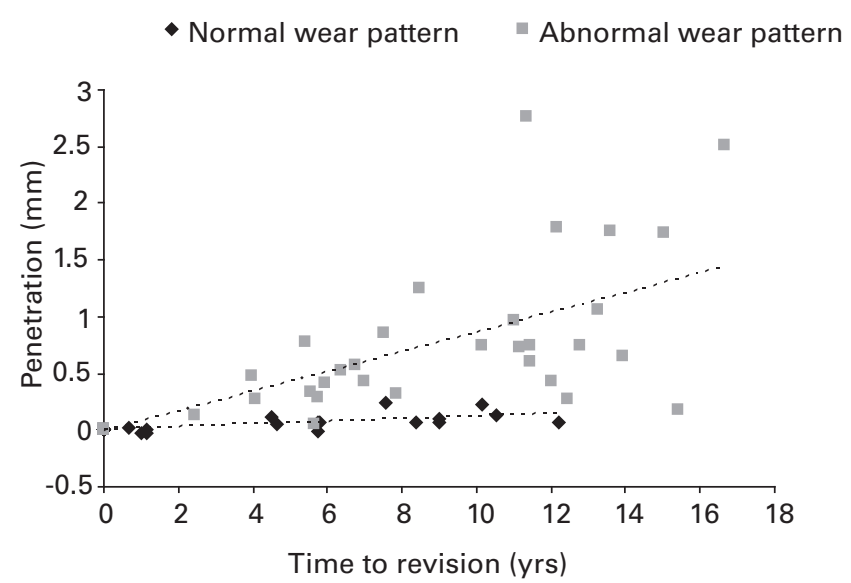

Fig. 3

The penetration $(\mathrm{mm})$ for bearings with normal and abnormal macroscopic appearance plotted against time (years). Linear regression lines for each group are included.

Figure 3 shows a comparison between estimated rates of linear penetration in bearings showing normal or abnormal macroscopic appearance. A $t$-test comparison of coefficients revealed that the rates of linear penetration $(0.01 \mathrm{~mm} /$ year and $0.08 \mathrm{~mm} /$ year $)$ were significantly different $(\mathrm{p}<0.001)$.

Linear penetration in the three groups identified by different surface wear patterns. Linear penetration was measured for the three groups and all had increasing penetration with time. There were differences in penetration between the groups (Fig. 4). The rate of linear penetration of group $C$ was approximately 2.5 times that of group $B$, and that of group $B$ was five times that of group A (Fig. 5). Pairwise comparisons show a statistically significant difference between all groups (ANOVA, $\mathrm{p}<0.001$ in all comparisons).

The rate of penetration between phase 1 and 2 bearings showed a significant difference $(t$-test, $\mathrm{p}=0.016)$ : phase 1 $(0.10 \mathrm{~mm} /$ year, $95 \%$ CI 0.04$)$ and phase $2(0.05 \mathrm{~mm} /$ year,

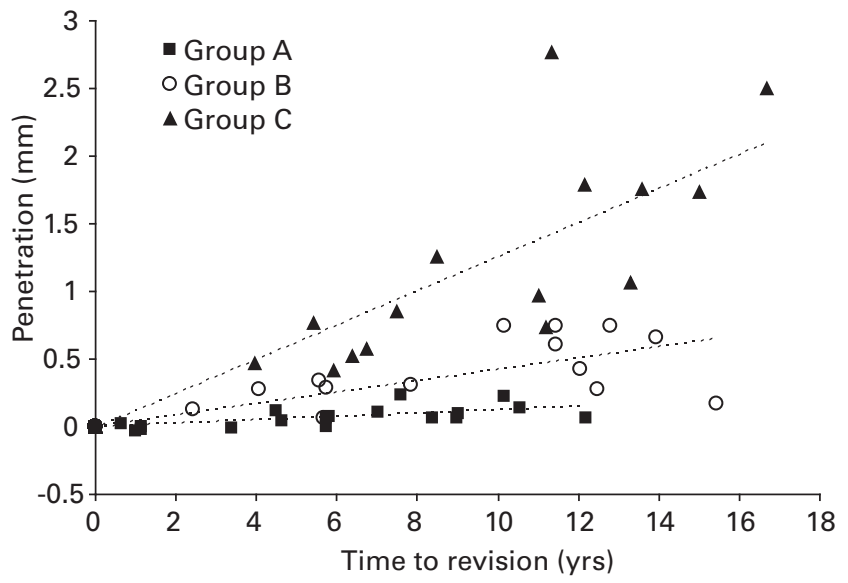

Fig. 4

The penetration ( $\mathrm{mm}$ ) for different subgroups. Group A, No abnormal macroscopic wear and a normal articular surface; group $B$, abnormal macroscopic wear and normal articular surfaces with extra-articular impingement; group $\mathrm{C}$, abnormal macroscopic wear and abnormal articular surfaces with intra-articular impingement +/- signs of non-congruous articulation. Linear regression lines are shown, and in each case the gradient represents an estimate of rate of penetration ( $\mathrm{mm} / \mathrm{year}$ ).

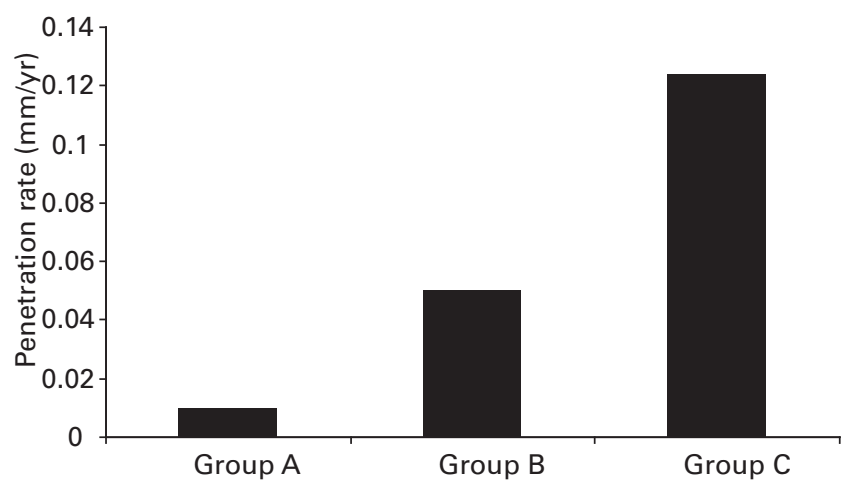

Fig. 5

Histogram comparing estimates of mean rate of linear penetration between groups $A, B$ and $C$.

95\% CI 0.01). There was a difference in the proportion of each phase with evidence of impingement. Of the 11 phase 1 bearings, ten displayed signs of impingement, whereas the proportion was much less in those in phase 2 (21 of 36 , $58 \%$ ) (chi-squared, $\mathrm{p}<0.029$ ).

There was no difference in the mean penetration between bearing thicknesses. The $3.5 \mathrm{~mm}$ bearings had a mean rate of linear penetration of $0.064 \mathrm{~mm} / \mathrm{year}$, the $4.5 \mathrm{~mm}$ bearings of $0.021 \mathrm{~mm} /$ year, the $5.5 \mathrm{~mm}$ bearings of $0.059 \mathrm{~mm} /$ year, and those bearings with a thickness $\geq 6.5 \mathrm{~mm}$ of $0.076 \mathrm{~mm} /$ year (ANOVA, $\mathrm{p}=0.112$ ).

\section{Discussion}

This study suggests that when functioning normally the Oxford UKR with a fully congruous meniscal bearing, is capable of achieving extremely low rates of wear. Of the 
$16(34 \%)$ of retrieved bearings that showed no evidence of abnormal macroscopic wear, other than some minor pitting, the calculated mean linear penetration was $0.01 \mathrm{~mm} /$ year. In contrast, $31(66 \%)$ of the retrieved bearings had evidence of abnormal wear patterns with higher rates of wear. These findings corroborate those of Psychoyios et $\mathrm{al}^{5}{ }^{5}$ who also described impingement with the Oxford UKR, and emphasise that abnormalities in function of the bearing can negate any potential benefit in wear rate observed with normal function. The retrieved bearings used in this study were representative of bearings from knees that had failed and not those that were functioning normally. Price et $\mathrm{al}^{14}$ have previously shown in a radiostereometry study that the rate of wear in well-functioning UKR, in young patients, is about $0.02 \mathrm{~mm} /$ year, so the subgroup of bearings with normal wear, at a mean rate of $0.01 \mathrm{~mm} /$ year, are likely to be representative of the majority of cases. Previously it has been suggested that factors such as impingement which cause abnormal wear also cause failure. ${ }^{5}$ The high incidence of bearings with abnormal wear in this study tends to support this conclusion, highlighting the need for careful surgery to ensure the bearing moves freely without impingement.

Differences were also found between the bearing that displayed impingement, suggesting a spectrum of abnormal patterns of wear. In all, 16 bearings showed extra-articular polyethylene loss, with a corresponding rate of linear penetration of $0.05 \mathrm{~mm} / \mathrm{year}$. The process of repetitive extraarticular impingement may release debris, which will cause third-body wear and is the most likely cause of the increased rates of penetration.

The bearings which had damage extending into the articular surface had a higher rate of linear penetration ( $0.12 \mathrm{~mm} /$ year). By definition, intra-articular impingement must interfere with the normal articulation of the prosthesis and may predispose it to repetitive short periods of incongruent articulation. A reduction in contact area would increase contact stress, contributing to an increase in the rate of linear penetration. The detrimental effects of impingement highlight the need for careful surgical technique in the adequate removal of retained osteophytes, cement, and the rim of bone left on the anterior aspect of the femur after milling.

The highest measurements of linear penetration were seen in nine patients who had macroscopic evidence of incongruent wear in addition to impingement. Of these, five had signs of a longitudinal step in the bearing surface indicative of long-standing incongruent articulation, and five showed bottom-side wear, potentially as a result of subluxation of the bearing off the back of the tibial base plate during high flexion, or because of bearing contact with retained cement on the tibial surface.

Although severe pitting appears to be a marker of abnormal function of the bearing, minor pitting can occur in those with low rates of penetration and may be part of the natural history of their ageing process. Delamination has not previously been described in Oxford meniscal bearings. In this series the effect was only seen in association with abnormal patterns of wear, again suggesting a relationship with incongruent function of abnormal bearings.

The two bearings with evidence of impingement and incongruous wear which were found to have fractured were both of the thinnest polyethylene insert available in the inventory, with a nominal thickness of $3.5 \mathrm{~mm}$. With calculated rates of linear penetration of over $0.14 \mathrm{~mm} / \mathrm{year}$, the loss of polyethylene appears to have weakened the bearings to the extent that they fractured. The mean time to fracture was nine years, and this pattern of wear is different from the early catastrophic wear and increase in sublaminar stress associated with UKRs. ${ }^{15,16}$ The analysis of the rates of penetration of polyethylene with different bearing sizes shows that the rate is not related to the nominal bearing thickness. The four $3.5 \mathrm{~mm}$ bearings that showed normal macroscopic wear all had rates of wear of less than 0.02 $\mathrm{mm} /$ year. With this rate it would take approximately 175 years for the bearing to wear through. This supplies the evidence that thin bearings can be used safely without risk of fracture if normal function is achieved.

The aim of reducing polyethylene wear in knee replacement is to increase the survival of an implant, partly by reducing the theoretical threat of polyethylene debris-induced osteolysis. The mean rate of wear of $0.01 \mathrm{~mm} / \mathrm{year}$ found in bearings with no evidence of abnormal macroscopic wear compares favourably with the published results of polyethylene penetration with other forms of arthroplasty that use a metal-onpolyethylene construct. ${ }^{17-19}$ The value is approximately ten times less than the rates of penetration of $0.1 \mathrm{~mm} /$ year to $0.2 \mathrm{~mm} /$ year reported for total hip replacement. ${ }^{17-19}$

A limitation of this study is the lack of direct measurement of volumetric wear. In normally functioning Oxford UKRs a rate of linear penetration of $0.01 \mathrm{~mm} /$ year to $0.02 \mathrm{~mm} / \mathrm{year}$ would produce a volumetric rate of wear of $6 \mathrm{~mm} /$ year to $12 \mathrm{~mm}^{3} /$ year, as the area of bearing articular surface is approximately $6 \mathrm{~mm}^{2}$, which is significantly less than that seen in total hip replacement, where up to $90 \mathrm{~mm}^{3} /$ year has been reported. ${ }^{17}$ The volumetric wear will be significantly higher in Oxford UKRs with abnormal articulation. A further limitation of the study is the bias introduced by studying retrieval specimens. The fact that revision was required would suggest that abnormal function of the replacement was more likely. The mean rate of penetration for the entire group $(0.07 \mathrm{~mm} /$ year) would be expected to be higher than that seen in UKRs that are functioning and have not been revised. This is supported by a previous study of in vivo wear in the Oxford UKRs that were functioning well, where a rate of penetration of $0.02 \mathrm{~mm} /$ year was described. ${ }^{14}$

Despite many published retrieval studies there are few reports of the rate of linear penetration in total knee replacement (TKR). In 1993, Plante-Bordeneuve and Freeman ${ }^{20}$ reported an average rate of wear of $0.025 \mathrm{~mm} /$ year for a conforming TKR with a large contact area. Contemporary unconstrained TKRs have rates of penetration 
of around $0.2 \mathrm{~mm} /$ year, reflecting their lower contact area. $^{21}$ Ashraf et $\mathrm{al}^{22}$ reported a rate of penetration of $0.15 \mathrm{~mm} /$ year for the St Georg Sledge fixed-bearing UKR prosthesis. There are no other published rates of penetration for fixed-bearing devices, but early catastrophic polyethylene wear has been a problem with many designs, and it is likely that rates of linear penetration were high in these cases. $^{15,23,24}$

The Oxford UKR has the potential to achieve extremely low rates of wear, contributing to an improved survival of the prosthesis over TKR or fixed-bearing UKRs. Surgical technique, however, is critical to avoid any source of impingement or incongruent articulation, as this is associated with increased rates of polyethylene wear and may contribute to the need for revision surgery.

Financial support has been received from the National Institute for Health Research Biomedical Research Unit into Musculoskeletal Disease, Nuffield Orthopaedic Centre and University of Oxford.

The authors wish to acknowledge the contribution of D. J. Beard, D. J. Simpson and W. F. M. Jackson for help in collection and assessment of the bearings.

The author or one or more of the authors have received or will receive benefits for personal or professional use from a commercial party related directly or indirectly to the subject of this article. In addition, benefits have been or will be directed to a research fund, foundation, educational institution, or other nonprofit organisation with which one or more of the authors are associated.

\section{References}

1. Fisher J, Jennings LM, Galvin AL, et al. 2009 Knee Society Presidential Guest Lecture: polyethylene wear in total knees. Clin Orthop 2010;468:12-18.

2. Gupta SK, Chu A, Ranawat AS, Slamin J, Ranawat CS. Osteolysis afer total knee arthroplasty. J Arthroplasty 2007;22:787-99.

3. O'Connor JJ, Goodfellow JW. Theory and practice of meniscal knee replacement: designing against wear. Proc Inst Mech Eng [H] 1996;210:217-22.

4. Simpson DJ, Gray H, D'Lima D, Murray DW, Gill HS. The effect of bearing congruency, thickness and alignment on the stresses in unicompartmental knee replacements. Clin Biomech (Bristol, Avon) 2008;23:1148-57.

5. Psychoyios V, Crawford RW, O'Connor JJ, Murray DW. Wear of congruent meniscal bearings in unicompartmental knee arthroplasty: a retrieval study of 16 specimens. J Bone Joint Surg [Br] 1998;80-B:976-82.
6. Wright TM, Bartel DL. The problem of surface damage in polyethylene total knee components. Clin Orthop 1986;205:67-74.

7. Morris RW. Assessing the reliability of clinical measurement. In: Pynsent $P$, Fairbank JCT, Carr A, eds. Assessment methodology in orthopaedics. First ed. Oxford: Butterworth-Heinemann, 1997:1-18.

8. Altman D. Practical statistics for medical research. First ed. London: Chapman \& Hall, 1991.

9. Fleiss J, Levin B, Paik MC. Statistical methods for rates and proportions. Third ed. New York: Wiley, 1981:598-626.

10. Scott R, Schroeder D. Correlation of knee simulation to in-vivo use: evaluating the Oxford unicompartmental knee. Procs 46th Annual Meeting Orthopaedic Research Society, 2000:434.

11. Deng M, Latour RA, Ogale AA, Shalaby SW. Study of creep behaviour of ultrahigh-molecular-weight polyethylene systems. J Biomed Mater Res 1998;40:214-23.

12. Lee KY, Pienkowski D. Compressive creep characteristics of extruded ultrahighmolecular-weight polyethylene. J Biomed Mater Res 1998;39:261-5.

13. Bland JM, Altman DG. Statistical methods for assessing agreement between two methods of clinical measurement. Lancet 1986;1:307-10.

14. Price AJ, Short A, Kellett C, et al. Ten-year in vivo wear measurement of a fully congruent mobile bearing unicompartmental knee arthroplasty. J Bone Joint Surg [Br] 2005;87-B:1493-7.

15. Palmer SH, Morrison PJ, Ross AC. Early catastrophic tibial component wear after unicompartmental knee arthroplasty. Clin Orthop 1998;350:143-8.

16. Bartley RE, Stulberg SD, Robb WJ 3rd, Sweeney HJ. Polyethylene wear in unicompartmental knee arthroplasty. Clin Orthop 1994;299:18-24.

17. Kabo JM, Gebhard JS, Loren G, Amstutz HC. In vivo wear of polyethylene acetabular components. J Bone Joint Surg [Br] 1993;75-B:254-8.

18. Wroblewski BM. Direction and rate of socket wear in Charnley low-friction arthroplasty. J Bone Joint Surg [Br] 1985;67-B:757-61.

19. Schmalzried YP, Callaghan JJ. Wear in total hip and knee replacements. J Bone Joint Surg [Am] 1999;81-A:115-36.

20. Plante-Bordeneuve $\mathbf{P}$, Freeman MA. Tibial high-density polyethylene wear in conforming tibiofemoral prostheses. J Bone Joint Surg [Br] 1993;75-B:630-6.

21. Hoshino A, Fukouka Y, Ishida A. Accurate in-vivo measurement of polyethylene wear in total knee arthroplasty. J Arthroplasty 2002;17:490-6.

22. Ashraf T, Newman JH, Desai VV, Beard D, Nevelos JF. Polyethylene wear in a non-congruous unicompartmental knee replacement: a retrieval analysis. The Knee 2004;11:177-81.

23. Engh GA, Dwyer KA, Hanes CK. Polyethylene wear of metal-backed tibial components in total and unicompartmental knee prostheses. J Bone Joint Surg [Br] 1992;74B:9-17.

24. Lindstrand A, Stenstrom A, Lewold S. Multicenter study of unicompartmental knee revision: PCA, Marmor, and St Georg compared in 3,777 cases of arthrosis. Acta Orthop Scand 1992;63:256-9. 